\title{
Ética feminista e comunicação
}

\author{
Feminist ethics and communication \\ Ética Feminista y Comunicación \\ Aimée Vega Montiel ${ }^{l}$ \\ (aimeevm@servidor.unam.mx) \\ http://dx.doi.org/10.5216/cei.v14i2.22441
}

\begin{abstract}
Resumo
Este artigo centra-se no diálogo entre feminismo e comunicação, com o objetivo principal de fazer um chamado à aplicação da ética feminista de maneira transversal nos estudos de comunicação. Nesse sentido, além de buscar a incorporação do feminismo como uma linha a mais da nossa disciplina, tenta motivar uma ruptura que provoque uma reformulação dos princípios sobre os quais se constroem os objetos de estudos e as formas de abordá-los.
\end{abstract}

Palavras-chave: Ética Feminista. Comunicação.

\section{Resumen}

Este artículo se centra en el diálogo entre el Feminismo y la Comunicación, con un objetivo principal: el de llamar a la aplicación de la ética feminista de manera transversal a los estudios de comunicación. En este sentido, más allá de buscar la incorporación del Feminismo como una línea más de nuestra disciplina, lo que persigue es motivar una ruptura que provoque una reformulación de los principios sobre los que se construyen los objetos de estudio y la forma de abordarlos.

Palabras clave: Ética feminista. Comunicación.

\begin{abstract}
This article focuses on the dialogue Feminism-Communication with the objective to call to the trasversalization of the Feminist Ethics in the Communication Studies. More than just to seek the integration of Feminism as an additional line of research in our discipline, the main goal is to cause a turning point on the epistemogical, theorical and methodological principles of research.
\end{abstract}

Key Words: Feminist Ethics. Communication.

\footnotetext{
${ }^{1}$ Investigadora del Programa de Investigación Feminista del CEIICH de la UNAM
} 
Pensar éticamente es pensar en los demás

Victoria Camps

La ética es necesaria para darle sentido y dirección a los grandes procesos de cambio Victoria Camps

\section{Apuntes introductorios}

El Feminismo ha revolucionado al conocimiento científico, pues ha posibilitado una nueva visión desafiando al orden social más ancestral, universal y arraigado de los que existen: el patriarcado (Millet, 1996). Su objetivo es conceptualizar como conflictos y producto de relaciones de poder, hechos que se consideran normales y que se han naturalizado legitimando la dominación sexual. De ello deriva su intencionalidad política, que apunta, vía la justicia - universal, extendible a todas las personas- y el cuidado - esto es, la responsabilidad de atender las necesidades de las personas, en aras de realizar la igualdad -, a la transformación del Estado. Al cuestionar los modelos clásicos de ese conocimiento, planteando una nueva ética, el Feminismo se ha consolidado como una de las rutas teóricas fundamentales en el universo de la ciencia, reconocida, desde luego, por las autoras feministas (De Miguel, 2008), pero también por científicos clave en la teoría social, como Alan Touraine (2007), Pierre Bourdieu (2000) y Gilles Lipovetsky (2002). Y lo ha hecho desde la filosofía, la historia, la sociología, la economía, la teoría política, la antropología, el derecho y la comunicación. Esta revolución, tiene como base la reivindicación de las mujeres, no sólo como objeto (lo que se estudia) sino como sujetos de conocimiento (quien estudia).

Con esta base, este artículo se centra en el diálogo entre el Feminismo y la Comunicación, con un objetivo principal: el de llamar a la aplicación de la ética feminista de manera transversal a los estudios de comunicación. En este sentido, más allá de buscar la incorporación del Feminismo como una línea más de nuestra disciplina, lo que persigue es motivar una ruptura que provoque una reformulación de los principios sobre los que se construyen los objetos de estudio y la forma de abordarlos. 
La intencionalidad de este trabajo se basa en el reconocimiento de la habida resistencia de los estudios de comunicación de recurrir al diálogo con el Feminismo, lo cual constituye la ausencia más grave en los análisis de las políticas de comunicación, de la participación ciudadana, de la economía política y de las nuevas tecnologías de comunicación e información, entre otras líneas. Esta falta de visión, ha dejado como saldo un grave sesgo, y es el de no dar cuenta de las implicaciones que la evolución de las industrias culturales ha tenido para los derechos humanos de las mujeres, su desarrollo y ciudadanía.

En este contexto, es imperativo reconocer la importancia de la ética feminista para la investigación en comunicación, pues constituye un potencial transformador. En este tenor, y atendiendo al llamado de María José Sánchez y Alicia Reigada (2007), debemos evitar reducir el "género" a una categoría, y situarnos en ella como una perspectiva, necesaria, para la profundización en las implicaciones teórico-políticas de la relación mujeres y comunicación. Esta tarea es imperativa también para el análisis de la desigualdad y el poder y para explicar las causas estructurales de la subordinación de las mujeres, que se ven expresadas en los procesos comunicativos de representación, producción y recepción que han sido señalados.

\section{La ética Occidental, una ética del Patriarcado}

La ética, rama de la filosofía que a través de la reflexión racional, metódica y sistemática, apunta a reformular los criterios de acción universalmente válidos para que los seres humanos se realicen en su convivencia humana, no consideró en sus definiciones a la mitad de la población de este mundo.

Desde Aristóteles, hasta Kant, pasando por Habermas, la ética occidental no tuvo desde sus orígenes un carácter incluyente, pues fue pensada para orientar las relaciones en la esfera pública de la cual las mujeres fueron excluidas desde la fundación de la Modernidad. Tampoco lo fue pues asumió que las personas deliberaban de manera libre y racional, enfatizando el supuesto carácter individualizado de la sociedad moderna, rasgos caracterizados por la ética feminista como típicamente masculinos de la sociedad occidental. Ésta, denominada como ética de la justicia, ha sido puesta a discusión y desmontada, en la teoría y en la práctica, por el Feminismo. 
Alison Jaggar (1992) afirma que la devaluación de las mujeres por la ética tradicional, o ética de la justicia, se hizo evidente desde sus orígenes en cinco terrenos. En el primero, mostrando menos interés en los temas de las mujeres, e incluso oponiéndolas a los hombres en sus capacidades y acciones. Filósofos como Aristóteles y Rousseau, prescribieron la obediencia y la sumisión como virtudes femeninas dada, según ellos, la ausencia de características del sujeto moderno en las mujeres razón, autonomía e independencia-, argumentos que utilizaron para definirlas como instrumentos de las instituciones del patriarcado - empezando por la familia y abarcando a todo el Estado-.

En el segundo, juzgando como triviales los temas morales de la esfera doméstica, asociados al cuidado y la comunidad. Los filósofos modernos definieron las cuestiones del espacio doméstico, no sólo lejos, sino incluso en oposición al espacio público de la política, lo que hizo imposible discutir cuestiones como la justicia en la división sexual del trabajo, y legitimando la discriminación y la violencia contra las mujeres y las niñas en el espacio privado.

En el tercero, postulando que las mujeres no son moralmente maduras ni con la capacidad de profundizar, como los hombres, en los asuntos públicos. A Aristóteles y Rousseau, se sumaron otros filósofos como Kant, Hegel y Freud quienes en sus tratados acusaron la falta de razón moral de las mujeres.

En el cuarto, favoreciendo las formas masculinas de la razón moral que enfatiza las reglas, los derechos, la universalidad y la imparcialidad, opuestos a las relaciones, las responsabilidades, la particularidad y la parcialidad, asociadas éstas a la razón moral femenina.

Y en el quinto, ensalzando a los que se les definió como valores masculinos, en oposición a los femeninos:

VALORES MASCULINOS

Independencia

Autonomía

Razón

Voluntad

Jerarquía

Dominación

\section{VALORES FEMENINOS}

Interdependencia

Comunidad

Emoción

Obediencia

Horizontalidad

Sumisión 


$\begin{array}{ll}\text { Cultura } & \text { Naturaleza } \\ \text { Producto } & \text { Proceso } \\ \text { Guerra } & \text { Paz } \\ \text { Muerte } & \text { Vida } \\ \text { Ascetismo } & \text { Disfrute }\end{array}$

Es por ello que la ética feminista se trazó desde sus inicios el propósito de revisar, desmontar y reformular aquellos aspectos de la ética tradicional que promueven la subordinación de las mujeres. Y fue más allá, pues no se ha limitado a un solo dominio, sino que ha trascendido y ampliado las preocupaciones centrales de la ética introduciendo temas que no habían sido considerados de su dominio, como el cuidado, el trabajo doméstico y la sexualidad.

En esta línea, la historia de la filosofía de Occidente incluye numerosas críticas a la subordinación de las mujeres, identificadas en las obras de Mary Wollstonecraft, A Vindication of the Rights of Women (1792), The Subjection of Women (1869), de John Stuart Mill, The Origin of the Family, Private Property and the State (1884), de Federico Engels, y The Second Sex (1949), de Simone de Beauvoir, y se visibilizó en acciones como las promovidas por las sufragistas, y que se concretaron en el reconocimiento a la ciudadanía de las mujeres.

En su trayectoria, a finales de los años 60, y en el contexto de la Segunda Ola del Feminismo, el debate ético feminista se articuló alrededor de temas como la igualdad, la violencia, la sexualidad, el aborto, el trabajo doméstico y los estereotipos sexistas en los medios de comunicación. En los 80, desde la academia y los movimientos sociales, las feministas introdujeron al debate temas como la pornografía, la tecnología reproductiva, el medioambiente y la situación de las mujeres en los países en desarrollo.

En esta década, el trabajo de Carol Gilligan, In a Different Voice (1982), fue el primero en demostrar empíricamente las formas en que las mujeres y los hombres piensan sobre cuestiones éticas, arribando a la conclusión de que el género determina diferentes visiones sobre estos asuntos. En este trabajo tiene sus orígenes la ética del cuidado. De acuerdo con las evidencias, mientras que los hombres construyen su identidad sobre el principio de diferenciación de los otros, las mujeres la construyen a partir de sus relaciones con esos otros. Ello ha permitido suponer que la ética del cuidado 
es producto de la lógica de las relaciones, que contrasta con la lógica formal de la imparcialidad, propia de la ética de la justicia. Mientras que la ética de la justicia deriva de la premisa del individualismo, la ética del cuidado descansa sobre la premisa de la responsabilidad con los otros.

Podemos afirmar que la aportación central de la ética del cuidado radica en haber colocado el compromiso y la responsabilidad con los otros en el centro de la acción moral.

El trabajo de Gilligan puso también de relieve otras formas de práctica ética que no corresponden con el modelo de Occidente, pero que son igualmente importantes y fundamentales para el sostenimiento de la sociedad. Esas formas de la práctica ética occidental a las que su trabajo nos refiere son:

1. Racionalidad. La ética tradicional ponía énfasis en la racionalidad, negando los sentimientos en la toma ética de decisiones. En este punto, Gilligan demuestra que los sentimientos son centrales en la toma de decisiones éticas, en las que el cuidado y las relaciones con los otros tienen un papel central.

2. Universalidad y Abstracción. La filosofía occidental defendía el principio de universalidad, equivalente al de imparcialidad, en las consideraciones éticas. La ética feminista ha probado que no hay puntos de vista imparciales, pues en todas las decisiones intervienen los puntos de vista de la persona que las toma; así también, que las visiones universales abstraen los análisis y las acciones de situaciones concretas.

3. Individualismo. Filósofos como Kant defendían la existencia de un punto de vista individual sobre el mundo, en donde separación y autonomía eran vistas como condiciones fundamentales para la toma de decisiones, y en donde la distancia respecto a los otros en las decisiones morales era vista como virtud. Lo que no asumía este supuesto, es que las personas forman parte de relaciones y de ambientes, y que por tanto tienen responsabilidades con su entorno, es decir, que deben asumir un cuidado sobre los demás (Palmer, 2010).

4. Objetividad. Puesto que la Ilustración concebía al hombre como autónomo e individual, ensalzaba la objetividad en las consideraciones éticas como cualidad central del sujeto moderno. Sin embargo, el Feminismo, en diálogo con el Marxismo, el Psicoanálisis, el Comunitarismo y el Postmodernismo, ha argumentado que la subjetividad está determinada por 
las relaciones con los otros, y prioriza los valores del cuidado, la atención y el afecto complementarios a los principios de la igualdad, el respeto y los derechos.

En este punto, es importante aclarar que el objetivo de la ética feminista no es el de defender que las mujeres y sus prácticas son mejores que las realizadas por los hombres, sino demostrar que ambos tienen capacidades que comparten pero que la estructura social les niega manifestar y llevar a la práctica. Eso sí, la ética feminista asume que las mujeres y los hombres no están situados de forma similar en la sociedad, y también, que las mujeres no son idénticas, sino que las reconoce en sus identidades y contextos específicos. Esto último ha permitido entender las acciones individuales en el contexto amplio de la estructura social e identificar manifestaciones de dominación y control, pero también de resistencia y emancipación.

En conclusión, el Feminismo ha apostado por una complementariedad - que no por una sustitución- de la ética del cuidado y la ética de la justicia, en tanto una práctica social de responsabilidad -amor y compasión- con los otros, y no sólo como una elección individual:

La justicia y el cuidado no se plantean como dos alternativas excluyentes, sino acumulativas. La ética de la justicia nos centra en el imperativo de no admitir excepciones (...), y la ética del cuidado nos propone el deber y la responsabilidad por atender las necesidades para que la equidad y la igualdad real se produzcan (CAROSIO, 2007, p. 13).

\section{Las claves de la ética feminista}

A la vista de lo expuesto, sostenemos que el Feminismo ha realizado contribuciones significativas a la teoría y la práctica Ética, y que la ha redefinido desarrollando aproximaciones dirigidas a respetar la experiencia moral de las mujeres y, en un marco más amplio, a promover una convivencia humana basada en el principio del bienestar colectivo.

De acuerdo con Alison M. Jaggar (1992), el Feminismo ha sido determinante en la reorientación de la ética poniendo en práctica las siguientes acciones: 
1. Visibilizar la importancia de los intereses de las mujeres. El trabajo del Feminismo en la ética práctica se identifica por el empleo de la categoría Género como clave para el análisis de la ética: su uso ha revelado que muchas prácticas políticas no son neutrales, pero sí opresoras de las mujeres. Y aunque en la política formal poco a poco las mujeres van siendo enunciadas, en la práctica la discriminación prevalece, lo que evidencia que construir la igualdad de los sexos en el ámbito formal no se ha traducido en su realización en el ámbito sustantivo de la igualdad.

2. Ampliar el dominio de la ética. Como lo hemos argumentado, la ética occidental ha definido como temas del dominio moral muchos que excluyen a aquellos relacionados con las mujeres, por lo que uno de los objetivos que se trazó el Feminismo fue el de expandir la arena de la ética. De esta manera, varios temas introducidos por el feminismo y hoy reconocidos por la ética formal son los relacionados con el medioambiente, la bioética, la sexualidad, la violencia contra las mujeres, la representación de las mujeres en los medios de comunicación y el lenguaje sexista. Todos ellos con grandes implicaciones para la vida y la libertad de las mujeres y de toda la humanidad, por lo que, desde el Feminismo éstos no son caracterizados como temas exclusivos de ellas.

3. Repensar al sujeto moral. Una de las claves fundamentales del Feminismo, ha sido demostrar la capacidad de las mujeres para ejercer su autonomía moral y racionalidad, desmontando así el carácter masculino de estas categorías.

4. Reevaluar lo femenino. Las feministas han respondido a la filosofía occidental en lo que ésta ha definido como femenino, insistiendo en que el concepto y sus características deben ser reevaluadas. Ello ha permitido que, por ejemplo, desde la ética del cuidado, el Feminismo apunte a la ética de la justicia con el objetivo de reconceptualizar a las propias instituciones sociales para que fortalezcan las acciones dirigidas al cuidado de las personas.

5. Construir una experiencia moral de las mujeres. Hay otras aportaciones de las feministas, algunas muy recientes, que apuntan a terrenos como el de los derechos humanos, a los que desde la década de los 70 se logró empezar a desmontar y reconceptualizar con el objetivo de que incluyan a la mitad de la población del planeta. Desde esta perspectiva, las feministas consideran a la tradición de los derechos humanos un recurso valiosísimo para la libertad de las 
mujeres, por lo que se ha apostado por una visión inclusiva y totalmente humana de los derechos humanos (frente al falso humanismo de las viejas visiones).

\section{Posibilidades de la ética feminista en la comunicación}

Llevada al terreno de nuestro análisis, la ética de la comunicación se ha ocupado de definir sobre lo que debe ser un proceso de comunicación para que las personas convivan, basándose en los principios de la ética de la justicia, esto es: racionalidad, universalidad, individualismo y objetividad. En esta línea, la ética de la comunicación ha sido definida por autores como Antonio Pasquali (2007) como una tarea de la razón práctica destinada a:

1. Alimentarse de los resultados empíricos de las investigaciones psico-sociales para derivar en abstracción, constantes y tendencias

2. Formular, sobre la base de los principios más universales de una justa convivencia, un modelo de deber ser del comportamiento comunicacional

3. Derivar los supremos principios normativos que pueden concretarse posteriormente en normas morales, normas políticas y normas jurídicas.

Esta visión normativa es sin duda valiosa, sin embargo, no pone de relevancia que la dignificación de los seres humanos es condición para la convivencia social, lo que hace imperativo recordar que los sujetos deben estar en el centro de la reflexión ética. En este sentido, podemos afirmar que una de las contribuciones iniciales de la ética feminista a la comunicación, es que esa posibilidad de traer al centro a las personas es observada como la oportunidad de realizar el Derecho Humano a Comunicar. Por esta razón, la ética feminista se ha pronunciado por la importancia de la comunicación como motor de los derechos humanos de las mujeres. Ello ha permitido conocer el desarrollo de las mujeres y sus posibilidades en el ámbito de la comunicación que se concretan en un acceso muy limitado de las mujeres a los medios de comunicación y las tecnologías de información, en términos de representación y de empleo. Las imágenes estereotipadas que sobre ellas prevalecen en estas industrias, así como su escasa participación como propietarias y productoras, han sido señaladas por las feministas como poderosas barreras que dificultan la universalidad de los derechos humanos. 
En este marco, la ética feminista considera que, puesto que las industrias de la comunicación forman parte integral de la cultura, debemos apuntar a soluciones éticas para mejorar las prácticas y contenidos de los productos de esta industria. Por ello, y derivado de los análisis con los que se cuenta, Linda Steiner (2009) define cuatro ámbitos de aplicación de la ética feminista a la comunicación:

1. Aplicación de los conceptos clave de la ética feminista, como el de cuidado, al tratamiento periodístico, a fin de promover un periodismo responsable y promotor del bienestar social. Esta aplicación motivaría a los periodistas a asumirse como parte de lo que analizan y a desarrollar su capacidad de ser responsables con su comunidad.

2. La utilidad de la ética feminista para resolver dilemas éticos propios de la práctica profesional, con el fin de impulsar el acceso y participación libre e igualitaria de las mujeres en las industrias de la comunicación y la cultura. En esta línea, la ética feminista propone formas alternativas de organización en dichas industrias, de carácter horizontal, flexible y rotativo, más que burocrático y rígido, con el propósito de que más mujeres puedan sumarse al espacio institucionalizado de los medios de comunicación. Otra de las problemáticas que podemos incluir en este punto, es el de la visibilidad del sexismo y el acoso sexual en las industrias de comunicación gracias a la aplicación de la ética feminista.

3. Su incidencia en el ámbito de la representación mediática, con el fin de erradicar los estereotipos sexistas y promover representaciones de las mujeres reales y diversas.

4. Su papel en la erradicación de la discriminación y la violencia de género prevalecientes en los discursos audiovisuales y periodísticos, y en el propio sistema de propiedad de las industrias.

Aunado a ello, observamos que la ética feminista puede ser útil en el campo de la comunicación para reconceptualizar términos como el de Objetividad. Para el Feminismo, la objetividad puede ser la vía para identificar, denunciar y transformar el sexismo prevaleciente en la producción de conocimientos, en donde las mujeres no han figurado como sujetos de la ciencia. La otra objetividad, la objetividad sexista, producto de la filosofía moderna proveniente del siglo XVII, acuñó una dicotomía genérica que excluyó a las mujeres del universo del conocimiento -subjetivo/objetivo, cuerpo/mente, naturaleza/cultura, emoción/razón- y que distorsionó la forma de ver la vida y el conocimiento 
científico, codificando la realidad como masculina y femenina. Por ello, la propuesta de la investigación feminista es la de transformar la perspectiva existente sobre la objetividad y convertirla en herramienta para lograr que el conocimiento científico sea incluyente. Llevado a los estudios de comunicación, esta categoría ha sido clave para identificar las visiones estereotipadas de los medios de comunicación sobre las mujeres y los hombres, y sus relaciones.

\section{Lo que ha resultado del diálogo}

Llevada al terreno de la investigación científica, la Ética feminista ha logrado un diálogo muy fructífero con los estudios de comunicación, por lo que en la actualidad puede contar como conquista el haber situado a la comunicación en el centro del análisis y la acción en la agenda de derechos humanos de las mujeres.

El primer momento de esta relación se ubica en las investigaciones basadas en los análisis de contenido, entre los años 60 y 70, sobre la representación de las mujeres en el discurso mediático, impulsados por el objetivo de denunciar el sexismo en dicha representación. Un siguiente momento emanará de la confluencia entre la teoría feminista, el estructuralismo, la semiología y el psicoanálisis. En esta línea, el trabajo de Laura Mulvey (1975) buscaba denunciar la violencia simbólica contra las mujeres ejercida en el discurso cinematográfico.

La necesidad de ir más a fondo en la comprensión de la importancia que las industrias culturales tienen en la vida cotidiana de las mujeres, motivó la revalorización de géneros populares como las telenovelas (Moldeski, 1979; Hobson, 1982; Ang, 1985) y la literatura sentimental (Radway, 1988) productos con los que interactuaban principalmente las audiencias femeninas-, pues permitían analizar la subjetividad femenina y la relación de las mujeres con su entorno, sus prácticas, sus placeres, sus hábitos, y también, sus experiencias de interacción con los medios derivadas de su posición de subordinación en el espacio doméstico. En este punto, cabe aclarar que categorías como empoderamiento fueron traídas al análisis, intentando invocar a las mujeres como receptoras "resistentes", sin embargo, la propia realidad mostró que la aplicación de dicha categoría tenía ciertos límites, pues como Michelle Mattelart apunta, "lo que no se puede dejar de subrayar es que este empoderamiento de las mujeres se reduce a asumir sin culpabilidad el placer que les procuran los 
géneros de la televisión comercial y a defender esta cultura contra la imagen desvalorizada que tienen de ellos los hombres y ciertas feministas y, en general, una opinión marcada por la jerarquización de los bienes culturales" (MATTELART, 2007, p. 52).

A partir de ese momento, se incrementaron los esfuerzos en esta línea, de ahí que autores identificados con la corriente de los Estudios culturales, como David Morley (1986) y James Lull (1990), desarrollaran aproximaciones cualitativas, algunas de ellas etnográficas, para el análisis de la recepción, tomando en consideración la perspectiva feminista.

Por otro lado, en el marco de la Economía Política la investigación feminista ha promovido el análisis del poder en el ámbito de la comunicación, con el objetivo de develar la posición y actividades desarrolladas por las mujeres en las industrias culturales, pero también de determinar la forma en que la producción y programación de géneros como las telenovelas obedecen a la "producción de mercancías para una audiencia ya segmentada por la división del trabajo, especialmente por la división entre el trabajo doméstico, trabajo invisible, sin retribución económica, trabajo devaluado, y el trabajo que se realiza fuera del hogar" (MATTELART, 2007, p. 49).

En el caso particular de mi país, y acorde con el desarrollo de esta línea en el mundo, la investigación mexicana en Género y Comunicación ha registrado un avance notable ${ }^{2}$. El eje sobre el que mayor documentación encontramos, es el de la representación de las mujeres en el discurso mediático: del cine (AGUILAR, 1990; SÁNCHEZ, 1996; TUÑÓN, 1998); de la televisión (ALBARRÁN, CID, GONZÁLEZ, MUÑOZ y VELASCO, 1989; GALVÁN, 1995; MARTíNEZ, 1998; TABLATE, 1998; FONTEBOA, 2005; MEZA, 2007); de la prensa (CRUZ, 2004; HERNÁNDEZ, 2006; GUERRERO, 2006; PEIMBERT, 2007) y de las revistas para mujeres (GONZÁLEZ y SÁNCHEZ, 1984; GARCÍA, 1998). En este tenor, claves teóricas como perspectiva de género (CHARLES, 2002), representaciones sociales (VEGA MONTIEL, 2007b), roles de género (MARTÍNEZ, 1998) e identidad (FONTEBOA, 2005) han permitido explorar las posibilidades de la investigación feminista en el campo de la representación mediática. Cabe hacer notar que uno de los esfuerzos de carácter colectivo más significativos en este eje, ha sido el impulsado en los años 90 por

\footnotetext{
${ }^{2}$ Para una revisión detallada acerca del desarrollo de este campo en México, se recomienda revisar el artículo "Género y Comunicación: las claves de una agenda académica y política de investigación", preparado por Aimée Vega Montiel y Josefina Hernández Téllez (2008, en prensa) para el libro La Comunicación en México: Una agenda de investigación, y que constituye un estado del arte sobre esta línea.
}

Comun. \& Inf, v. 14, n. 2, p. 3-18, jul./dez. 2011 
investigadoras provenientes de disciplinas como la psicología y la comunicación y que se materializó en la obra Estudios de Género y Feminismo I y II, dando cabida a un importante número de trabajos que evidenciaban la reproducción de estereotipos sexistas en el discurso de los medios de comunicación en México (PICCINI, 1998; ELÍAS, 1998; CHARLES, 1998).

En el eje de los estudios de recepción, la preocupación de las investigadoras ha estado motivada, principalmente, por el desarrollo de una educación para los medios con perspectiva de género (BUSTOS, 2004). En diálogo con categorías como identidad y género, el análisis de la recepción cinematográfica ha permitido explorar la interacción de mujeres y hombres con las producciones de cineastas mexicanas (IGLESIAS, 1999). En el terreno de la recepción televisiva, las aportaciones han sido novedosas por cuanto han combinado claves teóricas provenientes de distintos terrenos para conocer la interacción de las mujeres con la televisión en el marco de su vida cotidiana. Así, categorías como etnia y género han dialogado para conocer las prácticas asociadas al consumo televisivo de mujeres indígenas (MORALES, 2003); también, las de género, generación y clase para el análisis de la recepción de telenovelas (BUSTOS, 1998a y 1998b); y las de género y participación política para conocer la influencia de la comunicación en la decisión de voto de amas de casa (VEGA, 2004).

En el ámbito de la producción, la investigación mexicana ha dado cuenta de la participación de las mujeres en las industrias mediáticas y su acceso a los puestos de dirección y de toma de decisión (MORALES, 2006a y 2006b); y también, acerca de los problemas que las mujeres experimentan una vez que logran incorporarse a la industria (LÓPEZ y AGUILAR, 1995). En los estudios sobre cine, ha habido un interés particular por visibilizar el trabajo y la experiencia de las cineastas mexicanas (IGLESIAS, 1989; AGUILAR, 1994; RIGEN, 1995; MILLÁN, 1995 y 1999). Los estudios sobre prensa, han permitido conocer principalmente la participación y contribución de las mujeres al periodismo mexicano (HERRERA y OROZCO, 1991; FERNÁNDEZ DE LARA y LARA, 1997; INCLÁN, 1989 y 1992; HERNÁNDEZ, 2003 y 2006; HERNÁNDEZ TÉLLEZ, 2001 y 2007).

Por último, el diálogo entre feminismo y comunicación en México, registra un número importante de trabajos dirigidos a recuperar las aportaciones y experiencia de las mujeres en el ámbito de la comunicación alternativa, vía los medios tradicionales y las nuevas tecnologías (ROA, 1998; AGUINAGA, 1998; GARCÍA, 2003; ZEPEDA, 2005; SÁNCHEZ, 2007; SANDOVAL, 2007). 
En su conjunto, estos trabajos han contribuido al diagnóstico sobre la situación de las mujeres en el mundo, evidenciando el acceso muy limitado de las mujeres a los medios de comunicación y las tecnologías de información, en términos de representación y de empleo. Pero el avance ha sido fructífero, pues la perspectiva ética del feminismo ha logrado colocar la discusión acerca de la comunicación desde una perspectiva de derechos humanos como un asunto de primer orden en el mundo, de ahí que comunidades como la Internacional Association for Media and Communication Research (IAMCR) y la Internacional Communication Association (ICA) han asumido su responsabilidad impulsando la investigación en esta línea.

\section{Apuntes finales}

Puesto que el objetivo de la ética feminista es el de promover una conciencia humana en formas sanas y productivas y en construir las estructuras sociales y políticas para garantizar estos principios, tiene implicaciones fundamentales en las prácticas comunicativas de las sociedades y en su efecto en la promoción de los derechos humanos de las mujeres.

Su aplicación es imperativa y nos permitirá alcanzar una comunicación más humana -desde los análisis y la práctica-: una comunicación que asuma su responsabilidad con los otros, una comunicación comunitaria que promueva el respeto, que promueva la afectividad y la compasión que, como afirma la filósofa Amelia Valcárcel, es la que mantiene al mundo en movimiento.

\section{Referencias}

ANG, Ien. The Battle between television and its Audiences: the politics of watching television. In: DRUMMOND P. y PATTERSON R. (Coords.). Television in Transition, Londres: BFI, 1985. BYERLY y ROSS. Women and media: a critical introduction. Londres: Blackwell, 2006. BOURDIEU, Pierre. La dominación masculina. Barcelona: Anagrama, 2000. CAROSIO, Alba. La ética feminista: más allá de la justicia. Revista Venezolana de Estudios de la Mujer, Caracas, v.12, n.28, p.1-19, jun. 2007.

CASTAÑO, Carmen. Las mujeres y las tecnologías de la información: internet y la trama de nuestra vida. Madrid: Alianza Editorial, 2005.

DANSILIO, Sergio. La defensa de la objetividad en la epistemología feminista. Documento en línea, disponible en: <www.galileo.fcien.edu.uy/epistemologias_feministas.htm>. Acceso en: 15 abr. $20-$. 
ÁLVAREZ, Ana de Miguel. Movimiento feminista y redefinición de la realidad. Documento en línea, Disponible en: <www.nodoso.org/mujeresred/feminismo_ana_de_miguel_movimiento_ feminista.html>. Acceso en: 15 abr. 2008.

OLIVEIRA, Orlandina de y ARIZA, Marina. Un recorrido por los estudios de género en México: consideraciones sobre áreas prioritarias. Ponencia presentada en la reunión sobre Género y Desarrollo. Montevideo: Septiembre, 1999.

GARCÍA, Rolando. Sistemas Complejos. Barcelona: Gedisa, 2006.

GADAMER, Hans-Georg. La Herencia de Europa. Barcelona: Península, 1990.

GILLIGAN, C. In a different voice: psychological theory and women's development. Cambridge: Harvard University Press, 1982.

GUARÍN, Germán. Interdisciplinariedad: disciplina, sentido y hechura histórica. Documento en línea, disponible en: 〈www.ucm.edu.co/final/memorias_congreso/Interdisciplinariedad.pdf >. Acceso en: 15 abr. 2008.

JAGGAR, A. Feminist ethics: some issues for the nineties. Journal of Social Philosophy, [S.1.], v. 20, issue 1-2, p. 91-107, 1992.

HARDING, Sandra. Is science multicultural? postcolonialism, feminisms and epistemologies. Bloomington-Indianapolis: Indiana University Press, 1998.

. The science question in feminism. Ithaca, NY: Cornell University Press, 1986.

HOBSON, Dorothy. Crossroads: drama of a soap opera. Londres: Methuen, 1982.

LIPOVETSKY, Gilles. La tercera mujer: permanencia y revolución de lo femenino. Barcelona: Anagrama, 2002.

LULL, James. Inside family viewing: etnographic research on television's audiences. London:

Routledge, 1990.

MATTELART, Michelle. Mujeres y Medios: memorias de un pensamiento crítico. En: SÁNCHEZ, María José y REIGADA, Alicia. Crítica feminista y comunicación. Madrid: Comunicación Social Ediciones, 2007.

MILLET, Kate. Política sexual. Madrid: Cátedra, 1996.

MORIN, Edgar. La mente bien ordenada. Barcelona: Seix Barral, 2001.

MOLDESKI, Tania. Search for tomorrow in today's soap operas. Film Quaterly. 33 (1) 1979.

MORLEY, David. Family television. Londres: Comedia / Routledge, 1986.

MULVEY, Laura. Visual pleasure and narrative cinema. Screen, 16 (3).

ORTIZ GÓMEZ, Teresa. Feminismo, mujeres y ciencia. En: F. J. Rodríguez Alcázar, M. Medina

Doménech y J. A. Sánchez Cazorla (Eds.). Ciencia, tecnología y sociedad: contribuciones para una cultura de la paz. Granada: Universidad de Granada, 1997.

PALMER, C. Ethics theory and philosophical method. Lancaster University. Documento en línea, disponible en: <www.lancs.ac.uk/depts/philosophy.htm>. Acceso en: abr. 2010.

FEMINIST ethics. Stanford Encyclopedia of Philosophy. Disponible en: <http://plato.stanford.edu/ entries/feminism-ethics/>.

PASQUALI, A. Pensar la comunicación. Barcelona: Gedisa, 2007.

RADWAY, Janice. Reception study: etnography and the problems of dispersed audiences and nomadic subjects. En: Cultural Studies, 2 (3), 1988. p. 376-399.

SÁNCHEZ, María José y REIGADA, Alicia. Crítica feminista y comunicación. Madrid:

Comunicación Social Ediciones, 2007. 
SCHIEBINGER, Londa. The mind has no sex? women in the origins of modern science. Cambridge Mass: Harvard University Press, 1989.

STEINER, L. Feminist media ethics. En: WULKINS, L. y CLIFFORD, G. The handbook of mass media ethics. NY: Routledge, 2009. p. 366-380.

TOURAINE, Alan. El mundo de las mujeres. Barcelona: Paidós Estado y Sociedad 149, 2007. VEGA MONTIEL, Aimée. La decisión de voto de las amas de casa mexicanas y las noticias electorales televisadas. Tesis de doctorado. Barcelona: Universidad Autónoma de Barcelona, 2004. VEGA MONTIEL, Aimée y HERNANDÉZ Josefina. Género y comunicación: las claves de una agenda académica y política de investigación. En: La comunicación en México: una agenda de investigación. México: CEIICH-UNAM, PFCPyS-UNAM, UAM, UABC, AMIC, 2008.

VIDARTE, Paco. Feminismos filosóficos y teorías de género. Documento en línea, disponible en: $<$ http://www.eutsi.org/kea/feminismos/feminismos/feninismos-filosoficos-y-teorias-de-genero/3.feminismo-en-eeuu-critica-teoria-queer-y-ciborgs.html>. Acceso en: 15 abr. 2008. 